10 Holland AE, Hill K, Alison JA, et al. Estimating peak work rate during incremental cycle ergometry from the 6-minute walk distance: differences between reference equations. Respiration 2011; 81: 124-128.

11 Spruit MA, Pennings HJ, Janssen PP, et al. Extra-pulmonary features in COPD patients entering rehabilitation after stratification for MRC dyspnea grade. Respir Med 2007; 101: 2454-2463.
12 Jones PW, Quirk FH, Baveystock CM. The St George's Respiratory Questionnaire. Respir Med 1991; 85: Suppl. B, 25-31.

13 Salzman SH. The 6-min walk test: clinical and research role, technique, coding, and reimbursement. Chest 2009; 135: 13451352.

DOI: 10.1183/09031936.00120711

\title{
Killer weekends: can we do something?
}

\section{To the Editors:}

BARBA et al. [1] touched on the sensitive issue of the "weekend effect". There is no dearth of studies concluding that there is a relative lack of care on weekends. The main reasons for the weekend effect are staff shortage [2], relatively junior staff, lack of supervision, weekend covering staff not familiar with the case [3] and relatively tired staff after a whole week of work. Society has every right to demand the same high level of care on all days, as medical disorders do not observe weekends. Many doctors are already overworked; therefore, expecting them to work " $24 / 7$ " would be unjust and unrealistic and, in all possibility, could hamper their efficiency. Smartly managing rosters seems a viable option but, ultimately, this aims to have more staff working on weekends, which nobody likes [4] or can be forced to do. Moreover, the image of the doctor as an overworked person living a dull life may not be a healthy thing for the profession. In finding a solution, the concerns of both parties must be taken into account. Merely making a higher proportion of the staff work on weekends is also not a solution if they are overworked and tired. The trend for calling in offshore doctors from lower paying countries on weekends, such as from New Zealand to Australia, and from other European countries to the UK [5], is also not a healthy practice; such doctors, who have already worked over the week and are completely alien to the patient's condition, cannot do justice to patient care, except for providing false comfort. There cannot be a single solution to the problem. A multipronged strategy will be required to improve patient care on weekends, which may include the following. 1) Inculcating a greater sense of responsibility, service and pride among healthcare professionals. This may seem to be an impractical and archaic thought in the era of "professionalism", but has the capability to bridge the healthcare gap by providing more volunteers.
2) Providing extra incentives in the form of monetary gains or fewer working hours during the week. 3) Innovative changes in the working atmosphere, especially on weekends, to develop enjoyable workplaces may make working on weekends less painful.

\section{N. Dutt and K. Chaudhry}

Government Medical College and Hospital, Chandigarh, India.

Correspondence: N. Dutt, Pulmonary Medicine, Government Medical College and Hospital, Sector 32, Chandigarh 160030, India. E-mail: drnaveendutt@yahoo.co.in

Statement of Interest: None declared.

\section{REFERENCES}

1 Barba R, Zapatero A, Emilio Losa J, et al. The impact of weekends on outcome for acute exacerbations of COPD. Eur Respir J 2011; [Epub ahead of print DOI: 10.1183/09031936.00013211].

2 Tarnow-Mordi WO, Hau C, Warden A, et al. Hospital mortality in relation to staff workload: a 4-year study in an adult intensive-care unit. Lancet 2000; 356: 185-189.

3 Petersen LA, Brennan TA, O'Neil AC, et al. Does housestaff discontinuity of care increase the risk for preventable adverse events? Ann. Intern Med 1994; 121: 866-872.

4 Girotti MJ, Leslie K, Chinnick B, et al. Attitudes of surgical residents toward trauma care: a Canadian-based study. J Trauma 1994; 36: 101-105.

5 Allen I. Doctors crossing borders: Europe's new reality. CMAJ 2009; 180: 158-161. 